\title{
An investigation of university students' internet and game addiction with respect to several variables
}

\author{
Özlem ÇAKIR* ${ }^{*}$ Tuncay AYAS ${ }^{* *}$ Mehmet Barış HORZUM ${ }^{* * * *}$
}

\begin{abstract}
The purpose of this study was to investigate whether internet and game addiction of university students differ in regard to variables such as gender, grade, having computer and internet connection and game type which they prefer. The sample of this study consists of 996 students from Faculty of Educational Science at Ankara University and Education Faculty at Gazi University. In terms of gender variable, male students' internet and computer game addiction levels were significantly higher than females. It was found that there was no significant difference between internet and computer game addiction levels in terms of students' grade and game type variables. Students who have personal computers showed significantly higher levels of addiction to internet and computer game than those who don't have personal computers. The students who have internet connection showed significantly higher levels of addiction to internet and computer game than those who don't have internet connection in their homes.
\end{abstract}

Keywords: Internet addiction, game addiction, addiction scale, demographic factors.

\footnotetext{
* Lecturer Dr., Ankara University, Faculty of Educational Sciences, Department of Computer Education and Instructional Technology, Ankara, Turkey. E-mail: ocakir@ankara.edu.tr ** Assist. Prof. Dr., Sakarya University, Faculty of Education, Department of Psychological Counseling and Guidance, Sakarya, Turkey. E-mail: tayas@sakarya.edu.tr

*** Assist. Prof. Dr., Sakarya University, Faculty of Education, Computer Education and Instructional Technology, Sakarya, Turkey. E-mail: mhorzum@sakarya.edu.tr
} 


\section{SUMMARY}

Purpose and Significance: In spite of the fact that computers provide convenience for people in many ways, their misuse may sometimes result in physiological and psychological damage on the users.Today people include computers in their lives to solve their questions easily.However, the over usage of them bring about internet and game addiction. Some researchers agreed that these types of addiction differentiate with gender, computer and internet ownership; on the other hand, some of the researchers disagree with this opinion. Because of the different findings in other culture research, this study aims to demonstrate whether game and internet addiction of university students vary according to specific variables such as gender, computer and internet ownership in Turkey.

Method: The study was planned and conducted in compliance with the survey methods. Initially, "Computer Addiction Scale for Adolescents" was administered to 1100 university students studying at the Education Faculties of two different state universities, namely Ankara and Gazi, located in Ankara, but only 996 of the completed forms were found to be appropriate to be included in the analysis of the study. Therefore, the sample of the study consists of 996 university students.

Results: First of all, the results of the study showed that the Internet and computer game addiction levels of male students were higher than that of female ones. It was found that there was no significant difference between internet and computer game addiction levels in terms of students' grade and game type variables. Students who have personal computers showed significantly higher levels of addiction to internet and computer game than students who don't have personal computers. Students who have internet connection showed significantly higher levels of addiction to internet and computer game than students who don't have internet connection in their homes.

Discussion and Conclusions: The results of the study showed that male students have higher levels of internet and computer game addiction compared to female students. These findings are consistent with the research conducted by Chou and Hsiao (2000), Chou, Londran and Belland (2005), Griffiths, Davies and Cappell (2004), Kubey, Lavin and Barrow (2001), Morahan, Martin and Schumacher (2000), Chou and Tsia (2007), Li and Kirkup (2007), Quaiser-Pohl et al. (2006), Passig and Levin (1999) and Scherer (1997). On the other hand, the findings of this research conflict with results of the studies carried out by Young (1996), Young (1998), Brenner (1997), Kim and Kim (2002). This outcome may result from students' awareness, usage aim and cultural gender role. In Turkey, male students have easier access to internet and computers compared to female students; therefore, this fact may have affected the results of the study which show that the male students are more addicted than female students. The second findings of this research support the idea that easy Internet access, Internet using skills, and time of Internet use result in internet addiction. 


\title{
Üniversite Öğrencilerinin İnternet ve Oyun Bağımlılıklarının Çeşitli Değişkenlere Göre İncelenmesi
}

\author{
Özlem ÇAKIR* ${ }^{*}$ Tuncay AYAS ${ }^{* *}$ Mehmet Barış HORZUM ${ }^{* * *}$
}

ÖZ. $\mathrm{Bu}$ araştırmanın amacı, üniversite öğrencilerinin internet ve oyun bağımlılıklarının cinsiyet, sınıf, evinde bilgisayar ve internet bağlantısı olma ve tercih edilen oyun şekli değişkenlerine göre farklılık gösterip göstermediğini ortaya koymaktır. Araştırmanın örneklemini, Ankara Üniversitesi Eğitim Bilimleri Fakültesi ve Gazi Üniversitesi’nin Eğitim Fakültesi'nde öğrenim gören 996 öğrenci oluşturmuştur. Araştırma sonucunda erkek öğrencilerin internet ve bilgisayar oyunu bağımlılığının kızlara göre daha yüksek olduğu bulunmuştur. Araştırmaya katılan öğrencilerin öğrenim gördükleri sınıflara ve tercih ettikleri oyun türüne göre internet ve bilgisayar oyun bağımlılığı açısından anlamlı farklılık olmadığı bulunmuştur. İnternet ve bilgisayar oyun bağımlılı̆̆ puanları ile bilgisayar ve internet bağlantısına sahibi olma arasında anlamlı bir ilişkinin olduğu belirlenmiştir.

Anahtar Sözcükler: İnternet bağımlılığı, oyun bağımlılığ1, bağımlılık ölçeği, demografik faktörler.

\footnotetext{
* Öğr. Gör. Dr., Ankara Üniversitesi, Eğitim Bilimleri Fakültesi, Bilgisayar ve Öğretim Teknolojileri Eğitimi Bölümü, Ankara, Türkiye. E-posta: ocakir@ankara.edu.tr

** Yrd. Doç. Dr., Sakarya Üniversitesi, Eğitim Fakültesi, Psikolojik Danıșma ve Rehberlik Bölümü, Sakarya, Türkiye. E-posta: tayas@ sakarya.edu.tr

*** Yrd. Doç. Dr., Sakarya Üniversitesi, Eğitim Fakültesi, Bilgisayar ve Öğretim Teknolojileri Eğitimi Bölümü, Sakarya, Türkiye. E-posta: mhorzum@ sakarya.edu.tr
} 


\section{GíRiş}

Günümüzde bilgisayarlar insanlara farklı alanlarda birçok kolaylık sağlamasına rağmen bazen amaçlarının dışında kullanılması insanlara fiziksel ve psikolojik açıdan zarar verebilmektedir. Özellikle gençlerin teknolojik gelişmeleri yakinen takip etmeleri sayesinde sahip olduğu bilgi ve beceriler onların bilgisayar karşısında daha fazla zaman harcamalarına neden olabilmektedir. Bilgisayar karşısında harcanan zamanın artması bireylerin sosyal, ailevi ve akademik hayatlarını olumsuz şekilde etkileyebilmektedir. $\mathrm{Bu}$ olumsuzlukların ortaya çıkmasına bilgisayarlar değil bilgisayarların amaçları dışında kullanılması neden olmaktadır (Young, 1996).

Bilgisayarların bireylerde meydana getirdiği memnuniyet ve sürekli istek duygusuyla aşırı kullanımı, bağımlılığa neden olmaktadır (Young, 1996). Kubey, Lavin ve Barrow (2001) bağımlı olan bireylerin sosyal hayat, iş hayatı ya da okuldaki akademik başarısının olumsuz şekilde etkilendiğini ve bu kişilerin kendilerini yalnız hissettiklerini belirlemişlerdir. Bireyler kendilerini yalnız hissettikleri durumlarda bu yalnızlığını bilgisayarda etkileşimli ortamlar olan internet ve oyunlarla gidermeye çalışabilmektedirler. Bağımlılıkla ilgili araştırmalar incelendiğinde de internet bağımlılığı ve internette oynanan oyun bağımlılığını konu edinen araştırmalara sıkça rastlanmaktadır (Cao, Su, Liu ve Gao, 2007; Chou, Condron ve Belland, 2005; Durdu, Hotomaroğlu ve Çağıltay, 2005; Ferraro, Caci, D'Amico, ve Di Blasi, 2007; Hollingsworth, 2005; Horzum, 2011; Kim, Lee, Han, Suh ve Kee, 2006; Onay, Tüfekçi ve Çağıltay, 2005; Young, 1996; Young, 1999).

Young (1996) ve Griffiths (2000) interneti aşırı derecede kullananların internette daha çok kumar, oyun, pornografi ve sohbet sayfalarını kullandıklarını ifade etmektedirler. Davis (2001) ise problemli internet kullanımını iki farklı boyutta incelemektedir. Bunlardan ilki özel problemli internet kullanımıdır. Bu kullanımda bağımlı olan insanlar genellikle belirli sayfaları (porno sayfaları, borsa, kumar, vb.) kullanmaktadırlar. İkincisi ise genel patolojik internet kullanıcılarıdır. Bu kullanıcılar ise yalnızca internette zaman harcarlar, belirli bir amaçları yoktur. İnterneti sosyalleşmek ya da zaman geçirmek için kullanırlar (Davis, 2001). Bu yönüyle internet bağımlılı̆̆ı düşünüldüğünde, bağımlılık genel ya da özel internet sayfası kullanımından kaynaklanabilmektedir.

Oyunlarla ilgili araştırmalara bakıldığında ise daha çok çevrim içi oynanan oyunlar ve kullanıcı profilleri ile ilgili araştırmalar karşımıza çikmaktadır (Bryce ve Rutter, 2006; Chumbley ve Griffiths, 2006; Griffiths, Davies ve Chappell, 2003; 2004; Hsu ve Lu, 2007; Michael, 2008; Rau, Peng ve Young, 2006; Wang ve Chang, 2004; Whang, 2005). Ancak oyunlar 
sadece internetle değil bilgisayar başında bireysel (Mario, vb.) ya da birlikte [yerel ăg (Counterstrike gibi) ve genel ă̆ (Ogame gibi) üzerinden] oynanabilmektedir (Griffiths, Davies ve Chappell, 2003). Bu yönüyle araştırmalarda bireysel ve yerel ağda birlikte oynanan oyunlara çok fazla yer verilmediği görülmüştür.

Alanyazın incelendiğinde, internet ve bilgisayar oyunu bağımlılığıyla ilgili cinsiyet, sınıf, evinde bilgisayar olup olmaması, internete erişim yeri gibi değişkenlerin incelendiği görülmektedir. Cinsiyetle ilgili araştırmalar incelendiğinde, erkeklerin kızlardan daha fazla internet bağımlısı olduğunu (Chou ve Hsiao, 2000; Chou, Londran ve Belland, 2005; Griffiths, Davies ve Cappell, 2004; Horzum, 2011; Kubey, Lavin ve Barrow, 2001; Morahan, Martin Schumacher, 2000; Scherer, 1997) k1zların erkeklerden bağımlı olduğunu (Young, 1996; Young, 1998) ve cinsiyet açısından anlamlı bir farkın olmadığını (Brenner, 1997; Kim ve Kim, 2002) belirten araştırmalara rastlanmıştır. Oyun bağımlılığıyla ilgili çalışmalarda da (Chou ve Tsia, 2007; Lee ve diğ., 2001 Akt. Kim ve Kim 2002; Li ve Kirkup, 2007; Quaiser-Pohl ve diğ., 2006; Passig ve Levin, 1999) cinsiyet değişkenine göre erkeklerin kızlardan daha fazla oyun bağımlısı olduğunu belirten araştırma bulgularına rastlanmıştır. Araştırmalar arasında farklı bulguların olduğu dikkate alınarak bu araştırmada cinsiyet değişkeninin incelenmesi gerektiğine karar verilmiş̧ir.

Sınıf değişkenine göre Kubey, Lavin ve Barrow'un (2001) çalışmaları incelendiğinde üniversite birinci sinıfta okuyan öğrencilerin daha fazla internet bağımlısı oldukları bulunmuştur. Alan yazında sınıf değişkeniyle ilgili çok fazla araştırma olmadığından bu araştırmada sınıf değişkeninin incelenmesine karar verilmiştir.

Bilgisayar sahibi olup olmama ve evden internete bağlanma ile ilgili Kim ve Kim'in (2002) araştırması internet bağımlısı olan bireylerin daha çok evden internete bağlandığı bulgusunu rapor etmektedir. Mümtaz (2001) çalışmasında çocukların bilgisayarı okuldan daha çok evde kullandıklarını belirtmiş ve evdeki bilgisayarlarda oyun oynamanın daha popüler olduğunu ifade etmiştir. Shi (2007) ise bilgisayar sahibi olanların, olmayanlara göre bağımlılık düzeyinin yüksek olduğunu ifade etmiştir. Bu bulgu, bilgisayar sahibi olmanın bağımlılı̆ga neden olmaktadır seklinde yorumlanmamalıdır. Burada bilgisayar sahipliğinin bireyin arzularına kolay ulaşma imkanı sağlaması bağımlılıkta önemli bir faktör olarak görülmesini sağlamaktadır. $\mathrm{Bu}$ durum aslında bağımlılığın kaynağı olarak bilgisayar sahipliğini görmenin dişında bir olgu içermektedir. Bilgisayar sahibi olma öğrencinin oyun ya da internet bağımlılı̆̆ düzeyini artıran bir faktör olarak görülmektedir. 
Bireylerin tek başına mı yoksa birlikte mi oyun oynadıklarına ilişkin araştırmalar incelendiğinde Griffiths ve Hunt (1995) evde ve tek başına bilgisayar oyunu oynayanların daha fazla bilgisayar oyunuyla zaman harcadığını ve daha fazla bağımlı olduğunu bulmuşlardır. Griffiths, Davies ve Cappell (2004) araştırmalarında birlikte oyun oynayanların oranının diğerlerinden daha fazla olduğunu belirtmişlerdir. Durdu, Hotomaroğlu ve Çağıltay (2005) ise üniversite öğrencilerinin tek kullanıcılı oyunları tercih ettiklerini belirtmektedirler.

Alanyazında cinsiyet değişkeniyle ilgili farklı bulguların olması, sınıf, bilgisayar sahibi olup olmama, internet bağlantısına sahip olup olmama ve tercih edilen oyun şekli değişkenleriyle ilgili fazla araştırmaya rastlanmaması nedeniyle araştırmada bu değişkenlerin ele alınmasına karar verilmiştir. Bu araştırmanın amacı; üniversitede okuyan öğrencilerin oyun ve internet bağımlılı̆̆ düzeylerinin cinsiyet, sınıf, bilgisayar ve internet bağlantısına sahip olma ve tercih edilen oyun şekli değişkenlerine göre farkl11ık gösterip göstermediği incelemektir.

\section{YÖNTEM}

Araştırma, tarama modeline uygun olarak planlanmış ve gerçekleştirilmiştir. Tarama modelinde; ilgilenilen olay, grup gibi birim ve duruma ait değişkenler, ayrı ayrı betimlenmeye çalışılır. Bu betimleme şimdiki zamanla sınırlı olabilir yani anlık durum saptamaları yapılabilir (Karasar, 2004). Bu araştırmada da üniversite öğrencilerinin internet ve oyun bağımlılıkları anlık saptama ile ortaya koyulmaya çalışı1mıştır. Araştırmanın evrenini Ankara Üniversitesi Eğitim Bilimleri ve Gazi Üniversitesi Eğitim Fakültelerinde okuyan öğrenciler oluşturmaktadır. Araştırmanın örneklemine 2006-2007 öğretim yılı bahar yarıyılında her iki üniversiteden eşit olacak biçimde toplam 1100 öğrenci seçilmiştir. Bu örneklemin seçiminde kota örnekleme yöntemi kullanılmıştır. Balcı'ya (1997: 89) göre bu yöntem yansız-random olmayan tabakalı örnekleme olarak görülebilir. Öyle ki her tabaka genelde tüm evren içindeki oranına göre örneklemde temsil edilmiştir. Araştırmada üniversitelerin her sınıfındaki sayı oranında araştırmanın örneklemine dahil edilmiştir. Her üniversiteden seçilen 550 öğrenci sınıflarının oranına göre toplam 1100 öğrenci araştırmaya dahil edilmiş̧ir. Bu öğrencilere ait verilerden 104 tanesi kullanılabilir bulunmadığ 1 ve aynı sorunun kontrol amaçlı ters sorusunu aynı cevabı verdikleri için araştırma dışında tutulmuştur. Araştırmada toplam 996 öğrencinin verisi kullanılarak sonuçlar elde edilmiştir. 
Tablo 1. Araştırmaya katılan öğrencilerin sinıfları ve üniversitelere göre dağıllımı

\begin{tabular}{lccc}
\hline & Ankara Üniversitesi & Gazi Üniversitesi & Toplam \\
\hline 1. Sinıf & 111 & 211 & 322 \\
2. Sinıf & 116 & 90 & 206 \\
3. Sinıf & 66 & 169 & 235 \\
4. Sınıf & 193 & 40 & 233 \\
Toplam & 486 & 510 & 996 \\
\hline
\end{tabular}

Araştırmaya katılan öğrencilerin \%30.3'ü erkek \%69.7'si ise kız öğrencilerinden oluşmaktadır. Bu durum cinsiyet değişkeni açısından büyük bir fark oluşturmaktadır. Eğitim fakülteleri evreninde de benzer şekilde kız öğrencilerin erkek öğrencilerden daha fazla olduğu gözlenmektedir. Ancak erkek ve kız öğrencilerin diğer değişkenlerdeki (sınıf, bilgisayar sahibi olma, internet bağlantısına sahip olma, oyun türü gibi) sayıları incelendiğinde erkek öğrencilerin gözeneklerdeki kişi sayıları 70'in altına düşmediğinden, dağılımı bozan bir yapının oluşturmadığı görülmüsstür.

Araştırmaya katılan öğrencilerin \%70.3'ü bilgisayar sahibi iken \%29.7'sinin bilgisayarı bulunmamaktadır. Öğrencilerin \%46.8'inin internet bağlantısı varken \%53.2'sinin internet bağlantısı bulunmamaktadır. $\mathrm{Bu}$ ögrencilerden \%63.3'ü internete evinden bağlanırken \%30.4 internet kafeden ve $\% 6.3$ 'ü okuldan internete bağlanmaktadır. Bunun yanında \%46.1'i birlikte, \%53.9'u ise tek başına oyun oynamaktadır.

Araştırmada, kullanılan veri toplama aracı Ayas, Çakır ve Horzum (2011) tarafindan geliştirilen "Ergenler için Bilgisayar Bağımlılığı Ölçeğì" kullanılmıştır. Ölçeğin özgünü lise öğrencilerine yönelik geliştirildiğinden, ölçeğin üniversite öğrencilerine uygun olması için maddelerde gerekli değişiklikler yapılarak geçerlik ve güvenirlik çalışmaları yapılmıştır.

$\mathrm{Bu}$ anlamda ölçeğin üç faktörlü olduğuna karar verilirken özdeğer-faktör sayıs1 grafiğine de bakmak gerekmektedir. SPSS paket programının verdiği özdeğer-faktör sayısı grafiği aşağıda yer almaktadır. Ölçek için yapılan geçerlik ve güvenirlik çalışmalarında araştırma için toplanan veriler kullanılmıştır. Ölçeğin geçerlik çalışmalarında öncelikle yapı geçerliliğini sınamak amacıyla açımlayıcı ve doğrulayıcı faktör analizi yapılmıştır. Yapılan faktör analizi sonucunda özgün formdan farklı olarak üç faktörlü bir yapı ortaya çıkmıştır. 


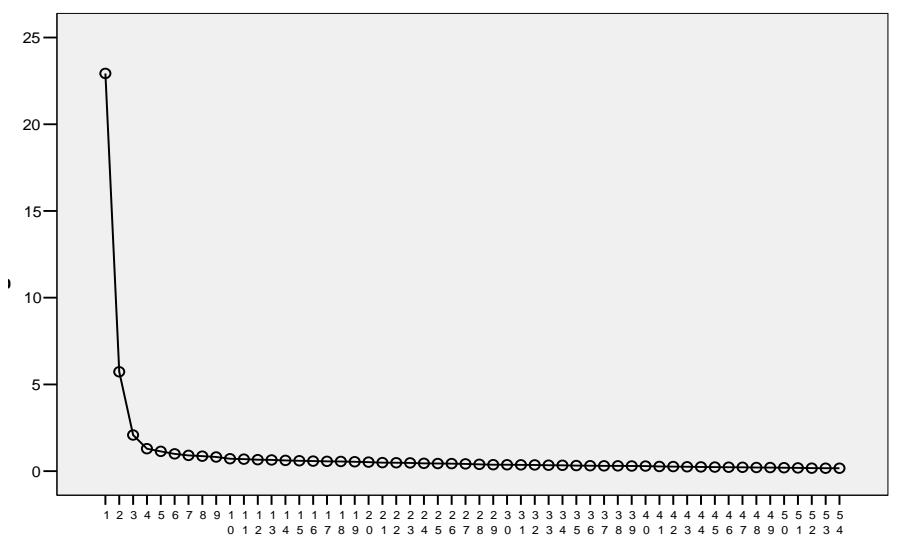

Şekil 1. Özdeğer-faktör sayısı grafiğ $i$

Özdeğer-faktör sayıs1 grafiği incelendiğinde ölçeğin üç faktörlü bir yapıya sahip olduğu görülmektedir. Açımlayıcı faktör analizinde D4., D9. ve D23. maddeler birden fazla faktörde .30'un üzerinde ve binişik (Büyüköztürk, 2005) faktör yüküne sahip olarak bulunmuştur. Bu nedenle D4., D9. ve D23. maddeler ölçekten çıkarılmıştır. Açımlayıcı faktör analizi sonuçları Tablo 2'de yer almaktadır.

Tablo 2. Ölçeğin açımlayıcı faktör analizi sonuçları

\begin{tabular}{lcccc}
\hline \multirow{2}{*}{ Madde } & \multirow{2}{*}{ Fak. Ort. Var. } & \multicolumn{3}{c}{ Faktörler } \\
\cline { 3 - 5 } C1 & & İnternet & Oyun & Oyun2 \\
C2 & .30 & .53 & \\
C3 & .39 & .59 & \\
C4 & .56 & .72 & \\
C5 & .52 & .68 & \\
C6 & .62 & .74 & \\
C7 & .42 & .56 & \\
C8 & .60 & .71 & \\
C9 & .53 & .67 & \\
C10 & .47 & .66 & \\
C11 & .56 & .61 & \\
C12 & .58 & .72 & \\
C13 & .63 & .73 & \\
C14 & .66 & .75 & \\
C15 & .46 & .63 & \\
\end{tabular}




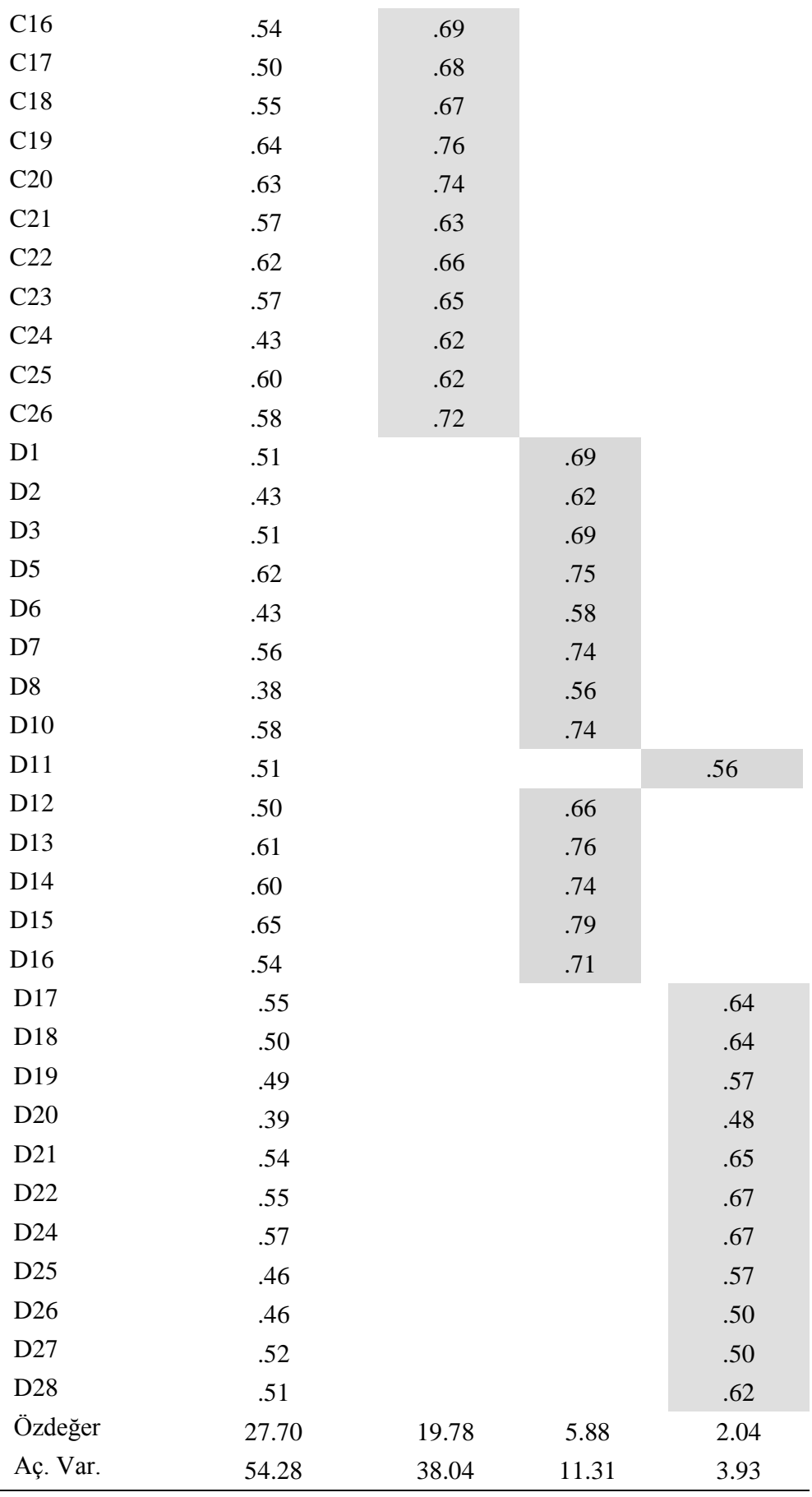


Tablo 2 incelendiğinde ölçekte yer alan ilk 26 madde birinci faktörü oluşturmaktadır. İnternet bağımlıı̆̆ 1 olarak adlandırılan bu faktör, toplam varyansın \%38.04'ünü açıklamaktadır. "Kendimi internete bağlanma zorunda hissederim" ifadesi bu faktörün örnek maddesidir. Ölçekte yer alan 13 madde ikinci faktörü oluşturmaktadır. Oyunu Başka Etkinliklere Tercih Etme ve Görevleri Aksatma olarak adlandırılan bu faktör, toplam varyansın \%11.31'ini açıklamaktadır. "Bilgisayarda oynadığım oyunu bitirmek için uykusuz kaldığım geceler olur" ifadesi bu faktörün örnek maddesidir. Ölçekte yer alan diğer 12 madde ise üçüncü faktörü oluşturmaktadır. Oyunu Bırakamama ve Gerçek Hayatla İlişkilendirme olarak adlandırılan bu faktör, toplam varyansın \%3.93'ünü açıklamaktadır. "Bilgisayarda oyunu bitirdikten sonra oyun esnasında yapmış olduğum hataları düşünürüm" ifadesi bu faktörün örnek maddesidir. 51 maddelik ölçeğin tamamı ele alındığında toplam varyansın \%54.28'sini açıklamaktadır. Bu yönüyle ölçek ölçmek istediği niteliği iyi derecede açıklayabilmektedir (Büyüköztürk, 2005).

Geriye kalan 51 madde için açımlayıcı faktör analizi ile elde edilen 3 faktörlü yap1 doğrulayıcı faktör analizi (DFA) ile test edilmiştir. DFA'da birinci düzey ve ikinci düzey analizleri yapılmıştır. Birinci düzey DFA sonucunda, uyum indeksi $\chi^{2}=8406.84(\mathrm{sd}=1221, \mathrm{p} .=.00), \chi^{2} / \mathrm{sd}=5.80$ RMSEA $=0.077$ olarak bulunmuştur. Yapılan birinci düzey DFA'da modifikasyon önerileri doğrultusunda C13. ile 12. maddeler, C23 ile 22. maddeler ve $\mathrm{C} 18$ ile 17. maddeler arasında istatistiki düzeltme içeren modifikasyon yapılmasına karar verilmiştir. Modifikasyon sonucunda uyum indeksleri $\chi^{2}=7070.87(\mathrm{sd}=1218, \mathrm{p} .=.00), \chi^{2} / \mathrm{sd}=6.88 \mathrm{RMSEA}=0.070$, $\mathrm{GFI}=0.78, \mathrm{AGFI}=0.76, \mathrm{CFI}=0.97, \mathrm{NFI}=0.97$ ve $\mathrm{NNFI}=0.97$ olarak bulunmuştur. Yapılan modifikasyonların $\chi^{2}$ (ki-kare)'ye anlamlı düzeyde ( $\mathrm{p}<$ .05) katkı sağladıkları görülmüştür.

Yapılan ikinci düzey DFA sonucunda, tanımlanan faktörlerin internet ve oyun bağımlılı̆̆ 1 örtük değişkenini anlamlı bir biçimde açıklayıp açıklamadığına bakıldığında, tüm faktörlerin örtük değişkeni anlamlı bir biçimde açıkladığ görülmüştür. İkinci düzey DFA sonucunda, uyum indeksi $\chi^{2}=8416.18(\mathrm{sd}=1221, \mathrm{p} .=.00), \chi^{2} / \mathrm{sd}=6.89$ RMSEA= 0.077, olarak bulunmuştur. Analizlerin modifikasyon önerileri doğrultusunda D6 ile Oyun 2 faktörü arasında, D18 ile C4. maddeler ve D26 ile oyun faktörü arasında istatistiki düzeltme içeren modifikasyon yapılmasına karar verilmiştir. Modifikasyon sonucunda uyum indeksleri $\chi^{2}=6763.33(\mathrm{sd}=1215, \mathrm{p} .=.0000)$, $\chi^{2} / \mathrm{sd}=5.56 \mathrm{RMSEA}=0.068, \mathrm{GFI}=0.79, \mathrm{AGFI}=0.77, \mathrm{CFI}=0.97, \mathrm{NFI}=0.97$ ve NNFI $=0.97$ olarak bulunmuştur. Yapılan modifikasyonların $\chi^{2}$ (kikare)'ye anlamlı düzeyde $(\mathrm{p}<.05)$ katkı sağladıkları görülmüştür. 


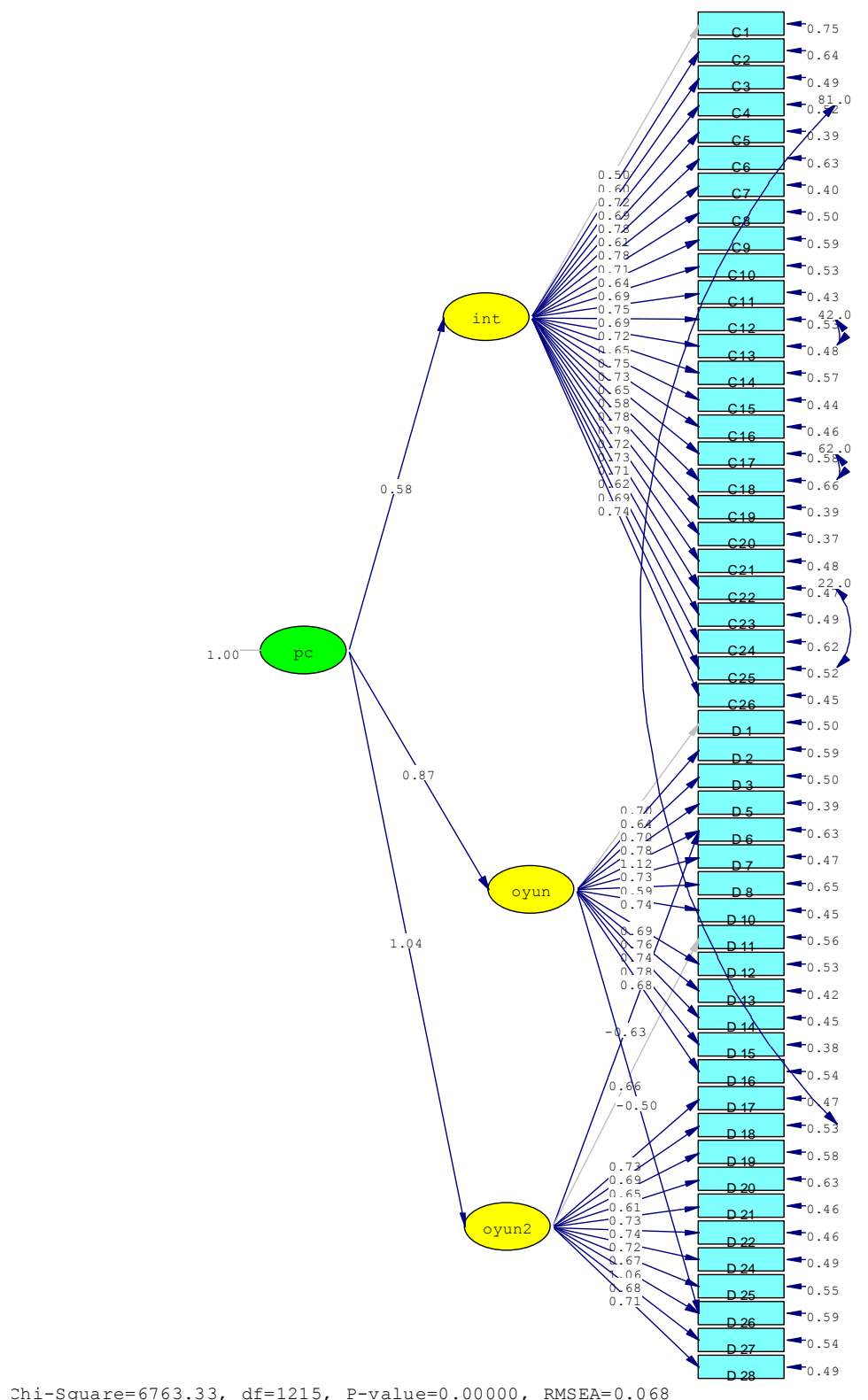

Şekil 2. Bilgisayar bağımlıllğı ikinci düzen DFA açıklama oranları ve hata varyanslarl 
Doğrulayıcı faktör analizi ile kurulan modellerin verilere uyumunun değerlendirilmesinde $\chi^{2}$, RMSEA, GFI, AGFI, CFI, NFI, NNFI gibi uyum indekslerine bakılarak değerlendirme yapılmaktadır. $\mathrm{Bu}$ değerlendirmede $\chi^{2} /$ sd oran 5 ve daha küçük olması durumunda model veri uyumunun çok iyi olduğu kabul edilmektedir. 5 'in üzerinde olduğunda kabul edilebilir veriler elde edilmiş olmaktadır. RMSEA değerinin sıfıra yakın ve 0.05 'den küçük olması model veri uyumunun mükemmel olduğunu göstermektedir. Fakat bu oranın 0.08 'e kadar veri uyumu için kabul edilebilmektedir. Ayrıca CFI ve AGFI indekslerinin 0.90 'dan büyük olması durumunda model veri uyumunun mükemmel olduğunu göstermektedir. CFI için 0.85 ve yukarısı; AGFI içinde 0.80 ve yukarısının model veri uyumu için yeterli olduğu kabul edilmektedir. CFI ve NNFI için ise 0.90 ve yukarısı model veri uyumunun mükemmelliğini göstermektedir (Anderson ve Gerbing, 1984; Sümer, 2000).

Ölçeğin uyum indeksleri incelendiğinde uyum indekslerinden GFI ve AGFI dışındakilerin kabul edilebilir düzeyde olduğu görülmektedir. GFI ve AGFI uyum indeksleri incelendiğinde bu indekslerin serbestlik derecesi, madde sayısı ve örneklem büyüklüğünden etkilenen indeksler olduğu görülmektedir (Şimşek, 2007). GFI ve AGFI gibi indeksler çok maddeli ölçek geliştirme ve çok değişkenli model araştırmalarında kullanılmayabilmektedir. Bu bulgulara dayanarak ölçeğin yapı geçerliliğinin sağlandığı ifade edilebilir. Ölçeğin güvenirlik çalışması için iç tutarlılık (Cronbach-alpha) katsayısı kullanılmıştır.

Ölçeğin bütününün iç tutarlık katsayısı .96 olarak bulunmuştur. Ölçeğin alt boyutlarına ilişkin iç tutarlılık kat sayıları ise şu şekildedir: İnternet Bağımlılı̆̆ 1 alt ölçeği için .95, "Oyunu Başka Etkinliklere Tercih Etme ve Görevleri Aksatma (OBETEGA)" alt ölçeği için .92 ve "Oyunu Bırakamama ve Gerçek Hayatla İlişkilendirme (OBGHi)" alt ölçeği için .91 olarak bulunmuştur. Bulunan bu değerler ölçeğin güvenirlik düzeyi için oldukça iyi olduğu söylenebilir.

Araştırmanın verileri 2006-2007 öğretim yılı bahar yarıyılı sonunda elde edilmiştir. $\mathrm{Bu}$ verilerin analizinde cinsiyet, bilgisayar ve internet bağlantısına sahip olma ve oynamayı tercih ettikleri oyun şekli için t-testi; bilgisayarı genelde kullandıkları yer ve öğrenim gördükleri sınıf için ANOVA testi yapılmıştır. Araştırmada tüm çözümlemeler SPSS paket programı kullanılarak gerçekleştirilmiş ve çözümlemelerde anlamlılık düzeyi olarak .05 kabul edilmiştir. 


\section{BULGULAR}

Araştırmada bulgular; cinsiyet, sınıf, bilgisayar sahibi olma, internet bağlantısına sahip olma ve tercih edilen oyun şekli sırasıyla sunulmuştur. $\mathrm{Bu}$ değişkenlere göre ölçeğin tüm maddelerini içeren toplam ve 3 alt faktörlü yapıda farklılık olup olmadığına bakılmıştır. Öncelikle cinsiyete ilişkin olarak ilişkisiz örneklemler için t-testi yapılmıştır. Test sonuçları Tablo 3 'te yer almaktadır.

Araştırmaya katılan öğrencilerin cinsiyetlerine göre internet bağımlılığ $\left(\mathrm{t}_{(977)}=9.99\right)$, OBETEGA $\left(\mathrm{t}_{(977)}=3.84\right)$, OBGHİ $\left(\mathrm{t}_{(977)}=6.25\right)$ alt faktörleri ve toplam $\left(\mathrm{t}_{(977)}=8.64\right)$ puanları arasinda istatistiksel olarak anlamlı farkl111k $(\mathrm{p}<.05)$ olduğu bulunmuştur. İnternet bağımlılığ öğrencilerin puanları ( $\bar{X}=43.72)$, kı öğrencilerin puanlarına $(\bar{X}=32.74)$ göre daha yüksektir. Araştırmaya katılan erkek öğrencilerin OBETEGA puanları $(\bar{X}=26.30)$, kız öğrencilerin puanlarına $(\bar{X}=23.66)$ göre daha yüksektir. Yine erkek öğrencilerin OBGHİ puanları $(\bar{X}=19.35), \mathrm{k} 1 \mathrm{z}$ öğrencilerin puanlarına ( $\bar{X}=16.10)$ göre daha yüksektir. Araştırmada erkek öğrencilerin bağımlılık toplam puanlarının $(\bar{X}=89.36)$, kız öğrencilerin puanlarına ( $\bar{X}=72.51)$ göre daha yüksek olduğu da bulunmuştur. $\mathrm{Bu}$ bulgular, erkek öğrencilerin kızlara göre internet ve bilgisayar oyunu bağımlılığının daha yüksek olduğunu gösterir niteliktedir. Başka bir ifade ile bağımlılık açısından cinsiyetin anlamlı bir değişken olduğu ortaya çıkmıştır.

Tablo 3. Internet ve oyun bă̆ımlılı̆̆ düzeylerinin cinsiyete göre değişim tablosu

\begin{tabular}{|c|c|c|c|c|c|c|c|}
\hline & Cinsiyet & $\mathrm{N}$ & $\bar{X}$ & SS & sd & $\mathrm{T}$ & $\mathrm{p}$ \\
\hline Internet & K1z & 688 & 32.74 & 10.40 & \multirow{2}{*}{977} & \multirow{2}{*}{9.99} & \multirow{2}{*}{.000} \\
\hline Bağımlılığ & Erkek & 291 & 43.72 & 17.48 & & & \\
\hline \multirow[t]{2}{*}{ OBETEGA } & $\mathrm{K} 1 \mathrm{z}$ & 688 & 23.66 & 9.80 & \multirow{2}{*}{977} & \multirow{2}{*}{3.4} & \multirow{2}{*}{.000} \\
\hline & Erkek & 291 & 26.30 & 9.88 & & & \\
\hline \multirow[t]{2}{*}{ OBGHİ } & $\mathrm{K} 1 \mathrm{z}$ & 688 & 16.10 & 6.09 & \multirow{2}{*}{977} & \multirow{2}{*}{6.25} & \multirow{2}{*}{.000} \\
\hline & Erkek & 291 & 19.35 & 7.93 & & & \\
\hline \multirow[t]{2}{*}{ Toplam } & $\mathrm{K} 1 \mathrm{z}$ & 688 & 72.51 & 22.45 & \multirow{2}{*}{977} & \multirow{2}{*}{8.64} & \\
\hline & Erkek & 291 & 89.36 & 29.91 & & & 000 \\
\hline
\end{tabular}

İkinci olarak öğrencilerin okudukları sınıflar arasında bağımlılık bakımından fark olup olmadığına bakılmıştır. Öğrenciler 1., 2., 3. ve 4. sınıfta okudukları için tek yönlü varyans analizi kullanılmıştır. Analiz sonucunda elde edilen veriler Tablo 4'te sunulmuştur. 
Tablo 4'te görüldüğg̈ gibi araştırmaya katılan öğrencilerin okudukları sınıflara göre internet bağımlılı̆ 1 puanları $\left(\mathrm{F}_{(3-975)}=1.37\right)$, OBETEGA puanları $\left(\mathrm{F}_{(3-975)}=1.67\right)$, OBGHİ puanları $\left(\mathrm{F}_{(3-975)}=0.80\right)$ ve toplam bağımlılık puanlarında $\left(\mathrm{F}_{(3-975)}=1.50\right)$ anlamlı farkl1l1k $(\mathrm{p}>.05)$ yoktur.

Tablo 4. Internet ve oyun bă̆ımlılı̆̆ ile öğrencilerin okudukları sınıflar arasındaki ilişkiyi gösteren ANOVA tablosu

\begin{tabular}{|c|c|c|c|c|c|c|c|c|c|c|}
\hline & Sinıf & $\mathrm{N}$ & $\bar{x}$ & SS & & $\begin{array}{l}\text { Kareler } \\
\text { toplamı }\end{array}$ & sd & $\begin{array}{l}\text { Kareler } \\
\text { Ort. }\end{array}$ & F & $\mathrm{p}$ \\
\hline \multirow{5}{*}{ 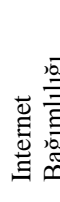 } & 1 & 319 & 36.94 & 14.03 & \multirow{2}{*}{ Gruplararası } & \multirow{2}{*}{786.46} & \multirow{2}{*}{3} & \multirow{2}{*}{262.15} & \multirow{5}{*}{1.37} & \multirow{5}{*}{251} \\
\hline & 2 & 203 & 34.42 & 13.72 & & & & & & \\
\hline & 3 & 227 & 36.08 & 13.79 & \multirow{2}{*}{ Gruplariçi } & \multirow{2}{*}{186748.50} & \multirow{2}{*}{975} & \multirow{3}{*}{191.53} & & \\
\hline & 4 & 230 & 36.03 & 13.74 & & & & & & \\
\hline & Toplam & 979 & 36.01 & 13.85 & Toplam & 187534.97 & 978 & & & \\
\hline & 1 & 319 & 24.42 & 10.00 & \multirow{2}{*}{ Gruplararası } & \multirow{2}{*}{489.65} & \multirow{2}{*}{3} & \multirow{2}{*}{163.21} & \multirow{5}{*}{1.67} & \multirow{5}{*}{171} \\
\hline \multirow{4}{*}{ 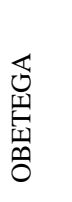 } & 2 & 203 & 23.18 & 9.41 & & & & & & \\
\hline & 3 & 227 & 25.18 & 9.76 & \multirow{2}{*}{ Gruplariçi } & \multirow{2}{*}{95130.38} & \multirow{2}{*}{975} & \multirow{3}{*}{97.57} & & \\
\hline & 4 & 230 & 24.89 & 10.22 & & & & & & \\
\hline & Toplam & 979 & 24.45 & 9.89 & Toplam & 95620.04 & 978 & & & \\
\hline \multirow{7}{*}{$\begin{array}{l}\text { 范 } \\
\text { है }\end{array}$} & 1 & 319 & 17.21 & 6.75 & \multirow{2}{*}{ Gruplararası } & \multirow{2}{*}{111.95} & \multirow{2}{*}{3} & \multirow{2}{*}{37.31} & \multirow{5}{*}{.80} & \multirow{5}{*}{496} \\
\hline & 2 & 203 & 16.47 & 6.99 & & & & & & \\
\hline & 3 & 227 & 17.00 & 6.28 & \multirow{2}{*}{ Gruplariçi } & \multirow{2}{*}{45731.86} & \multirow{2}{*}{975} & 4690 & & \\
\hline & 4 & 230 & 17.45 & 7.38 & & & & & & \\
\hline & Toplam & 979 & 17.07 & 6.85 & Toplam & 45843.81 & 978 & & & \\
\hline & 1 & 319 & 78.57 & 26.45 & & & & & & \\
\hline & 2 & 203 & 74.08 & 24.35 & 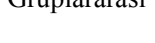 & 5042.41 & $J$ & 1014.15 & & \\
\hline & 3 & 227 & 78.26 & 25.52 & Gruplarici & ב 6609300 & 075 & 67787 & 1.50 & 214 \\
\hline वें & 4 & 230 & 78.37 & 27.37 & 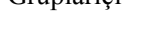 & 80070.02 & (1) & (2) & & \\
\hline & Toplam & 979 & 77.52 & 26.06 & Toplam & 663972.43 & 978 & & & \\
\hline
\end{tabular}

Üçüncü olarak internet ve oyun bağımlılığının bilgisayar sahibi olma değişkenine göre fark gösterip göstermediğine bakılmıştır. Öğrenciler bilgisayarı olan ve olmayan biçiminde sınıflandırıldığ 1 için ilişkisiz örneklemler için t-testi kullanılmıştır. Analiz sonucunda elde edilen veriler Tablo 5'de sunulmuştur.

Öğrencilerin internet bağımlılı̆̆ı alt faktöründen elde ettikleri puanlar, bilgisayarı olup olmamasına göre anlamlı bir farkl1lık göstermektedir $\left[\mathrm{t}_{(977)}=3.05, \mathrm{p}<.05\right]$. Bilgisayarı olan öğrencilerin internet bağımlılı̆̆ ( $\bar{X}=36.84)$, bilgisayarı olmayan öğrencilerin puanlarına $(\bar{X}=34.06)$ göre daha yüksektir. 
Tablo 5. Internet ve oyun bağımlıllğ değişseni arasındaki ilişkiyi gösteren t-testi tablosu

\begin{tabular}{|c|c|c|c|c|c|c|c|}
\hline & Kişisel PC & $\mathrm{N}$ & $X$ & SS & $\mathrm{sd}$ & $\mathrm{t}$ & $\mathrm{p}$ \\
\hline Internet & Evet & 685 & 36.84 & 14.33 & \multirow{2}{*}{977} & \multirow{2}{*}{3.05} & \multirow{2}{*}{.002} \\
\hline Bağımlılığ & Hayır & 294 & 34.06 & 12.46 & & & \\
\hline OBETEGA & Evet & 685 & 25.83 & 10.25 & \multirow{2}{*}{977} & \multirow{2}{*}{7.46} & \multirow{2}{*}{.000} \\
\hline & Hayır & 294 & 21.24 & 8.15 & & & \\
\hline OBGHİ & Evet & 685 & 17.68 & 7.19 & \multirow{2}{*}{977} & \multirow{2}{*}{4.72} & \multirow{2}{*}{.000} \\
\hline \multirow{3}{*}{ Toplam } & Hayır & 294 & 15.64 & 5.74 & & & \\
\hline & Evet & 685 & 80.35 & 26.65 & \multirow{2}{*}{977} & \multirow{2}{*}{5.53} & \multirow{2}{*}{.000} \\
\hline & Hayır & 294 & 70.93 & 23.37 & & & \\
\hline
\end{tabular}

Öğrencilerin OBETEGA alt faktöründen elde ettikleri puanlar, bilgisayarı olup olmamasına göre anlamlı bir farklılık göstermektedir $\left[\mathrm{t}_{(977)}=7.46, \mathrm{p}<.05\right]$. Bilgisayarı olan öğrencilerin OBETEGA puanları, bilgisayarı olmayan öğrencilerin puanlarına $(\bar{X}=21.24)$ göre daha yüksektir.

Öğrencilerin OBGHİ puanları, bilgisayarı olup olmamasına göre anlamlı bir farklılık göstermektedir $\left[\mathrm{t}_{(977)}=4.72, \mathrm{p}<.05\right]$. Bilgisayarı olan öğrencilerin OBGHİ puanları ( $\bar{X}=17.68)$, bilgisayarı olmayan öğrencilerin puanlarına ( $\bar{X}=15.64)$ göre daha yüksektir.

Öğrencilerin toplam bağımlılık puanları, bilgisayarı olup olmamasına göre anlamlı bir farkl11ık göstermektedir $\left[\mathrm{t}_{(977)}=5.53, \mathrm{p}<.05\right]$. Bilgisayarı olan ögrencilerin toplam bağımlılık puanları $(\bar{X}=80.35)$, bilgisayarı olmayan öğrencilerin puanlarına ( $\bar{X}=70.93$ ) göre daha yüksektir.

Dördüncü olarak internet ve oyun bağımlılığı ile öğrencilerin evlerinde internet bağlantısı olup olmadığı değişkeni arasındaki ilişkiye bakılmıştır. Öğrenciler evlerinde internet olan ve olmayan olarak sınıflandırıldığ ilişkisiz örneklemler için t-testi kullanılmıştır. Analiz sonucunda elde edilen veriler Tablo 6'da sunulmuştur.

Öğrencilerin internet bağımlılı̆̆ faktöründen elde edilen puanlar, evlerinde internet bağlantısı olup olmamasına göre anlamlı bir farklılık göstermektedir $\left[\mathrm{t}_{(977)}=2.23, \mathrm{p}<.05\right]$. Evlerinde internet bağlantısı olan öğrencilerin internet bağımlılı̆̆ puanları $(\bar{X}=37.07)$, internet bağlantısı olmayan öğrencilerin puanlarına ( $\bar{X}=35.08)$ göre daha yüksektir. 
Tablo 6. Internet ve oyun bağımlılĭğ ile ögrencilerin evlerinde internet bağlantısının olup olmadığı değiş̧keni arasındaki ilişkiyi gösteren t-testi tablosu

\begin{tabular}{|c|c|c|c|c|c|c|c|}
\hline & $\begin{array}{l}\text { İnternet } \\
\text { Bağlantıs1 }\end{array}$ & $\mathrm{N}$ & $\bar{X}$ & SS & $\mathrm{sd}$ & $\mathrm{t}$ & $\mathrm{p}$ \\
\hline Internet & Evet & 457 & 37.07 & 14.74 & 977 & 2.23 & 025 \\
\hline Bağımlılığ & Hayır & 522 & 35.08 & 12.96 & & & .025 \\
\hline \multirow[t]{2}{*}{ OBETEGA } & Evet & 457 & 25.48 & 10.10 & 977 & 3.06 & \multirow{2}{*}{.002} \\
\hline & Hayır & 522 & 23.55 & 9.62 & & & \\
\hline \multirow[t]{2}{*}{ OBGHİ } & Evet & 457 & 17.41 & 6.77 & 977 & 1.49 & \multirow{2}{*}{.137} \\
\hline & Hayır & 522 & 16.76 & 6.91 & & & \\
\hline \multirow[t]{2}{*}{ Toplam } & Evet & 457 & 79.96 & 27.12 & 977 & 2.74 & \multirow{2}{*}{.006} \\
\hline & Hayır & 522 & 75.38 & 24.92 & & & \\
\hline
\end{tabular}

Öğrencilerin OBETEGA alt faktöründen elde ettikleri puanlar, evlerinde internet bağlantısının olup olmamasına göre anlamlı bir farklılık göstermektedir $\left[\mathrm{t}_{(977)}=3.06, \mathrm{p}<.05\right]$. Evlerinde internet bağlantısı olan öğrencilerin OBETEGA puanları ( $\bar{X}=25.48)$, evlerinde internet bağlantısı olmayan öğrencilerin puanlarına $(\bar{X}=23.55)$ göre daha yüksektir. Öğrencilerin OBGHİ alt faktöründen elde ettikleri puanlar ile evlerinde internet bağlantısı olup olmama durumu arasında anlamlı bir fark bulunamamıştır $\left[\mathrm{t}_{(977)}=1.49, \mathrm{p}>.05\right]$.

Öğrencilerin toplam bağımlılık puanları evlerinde internet bağlantısının olup olmamasına göre anlamlı bir farkl11ık göstermektedir $\left[\mathrm{t}_{(977)}=2.74\right.$, $\mathrm{p}<.05]$. Evlerinde internet bağlantısı olan öğrencilerin toplam bağımlılık puanları $(\bar{X}=79.96)$, olmayanların toplam bağımlılık puanlarına $(\bar{X}=$ 75.38) göre daha yüksektir.

Beşinci olarak internet ve oyun bağımlılığı ile öğrencilerin birlikte veya tek başına oyun oynamayı tercih etme değişkeni arasında fark olup olmadığına bakılmıştır. Bu analiz için ilişkisiz örneklemler için t-testi kullanılmıştır. Analiz sonucunda elde edilen veriler Tablo 7'de sunulmuştur.

Öğrencilerin internet bağımlılı̆̆ faktöründen elde ettikleri puanlar, birlikte veya tek başına oyun oynamayı tercih etmelerine göre anlamlı bir farkl111k göstermemektedir [ $\left.\mathrm{t}_{(977)}=1.02, \mathrm{p}>.05\right]$. Yine öğrencilerin OBETEGA $\left[\mathrm{t}_{(977)}=1.48, \mathrm{p}>.05\right]$, OBGHİ $\left[\mathrm{t}_{(977)}=1.06, \mathrm{p}>.05\right]$ ve toplam bağımlılık $\left[\mathrm{t}_{(977)}=1.39, \mathrm{p}>.05\right]$ puanları, birlikte veya tek başına oyun oynamayı tercih etmelerine göre anlamlı bir farklılık göstermemektedir. 
Tablo 7. İnternet ve oyun bağımllliğı ile ögrencilerin birlikte veya tek başına oyun oynamayı tercih etme değişkenleri arasındaki ilişkiyi gösteren t-testi tablosu

\begin{tabular}{llllrlcc}
\hline & Oyun Türü & $\mathrm{N}$ & $\overline{\mathrm{X}}$ & $\mathrm{SS}$ & $\mathrm{sd}$ & $\mathrm{t}$ & $\mathrm{P}$ \\
\hline Internet & Bireysel & 528 & 36.42 & 13.85 & \multirow{2}{*}{977} & \multirow{2}{*}{1.02} & \multirow{2}{*}{.308} \\
Bağımlılı̆̆1 & Birlikte & 451 & 35.52 & 13.85 & & & \\
OBETEGA & Bireysel & 528 & 24.88 & 10.04 & 977 & \multirow{2}{*}{1.48} & .138 \\
& Birlikte & 451 & 23.94 & 9.70 & & & \\
OBGHİ & Bireysel & 528 & 17.28 & 7.11 & 977 & \multirow{2}{*}{1.06} & .288 \\
& Birlikte & 451 & 16.81 & 6.53 & & & \\
Toplam & Bireysel & 528 & 78.58 & 26.34 & 977 & \multirow{2}{*}{1.39} & .166 \\
& Birlikte & 451 & 76.27 & 25.69 & & & \\
\hline
\end{tabular}

\section{TARTIŞMA VE SONUÇ}

$\mathrm{Bu}$ araştırmada üniversitede okuyan öğrencilerin internet ve oyun bağımlılı̆̆ı düzeylerinin cinsiyet, sınıf, bilgisayar ve internet bağlantısına sahip olma ve tercih ettiği oyun şekli değişkenlerine göre farklılık gösterip göstermediklerini ortaya çıkarmak amaçlanmıştır. Bu amaç doğrultusunda öncelikle cinsiyet değişkeni incelenmiştir. Araştırma sonucunda erkek öğrencilerin kızlara göre internet ve oyun bağımlılığının daha yüksek olduğu bulunmuştur. Bu bulgu, Chou ve Hsiao (2000), Chou, Londran ve Belland (2005), Chou ve Tsia (2007), Griffiths, Davies ve Cappell (2004), Horzum, (2011), Kubey, Lavin ve Barrow (2001), Morahan-Martin ve Schumacher (2000), Li ve Kirkup (2007), Onay, Tüfekçi ve Çağıltay (2005), Passig ve Levin (1999) ve Scherer'in (1997), Quaiser-Pohl ve diğ. (2006) bulgularıla tutarlılık göstermektedir. Bunun yanında Young (1996), Young (1998), Brenner (1997), Kim ve Kim'in (2002) bulgularıla farkl1l1k göstermektedir. Stanford Üniversitesi'nde yapılan çalışmada erkeklerin kadınlara göre daha fazla oyun bağımlısı olduğu; bunun sebebinin oyun boyunca erkeklerin beynindeki doyum bölgesinin daha fazla aktif ifade edilmiştir (Wiki, 2008). $\mathrm{Bu}$ yönüyle üniversitedeki erkek öğrencilerin oyun bağımlılık düzeylerinin yüksek olması bu bulgu ile ilişkilendirilebilir. Ayrıca Türkiye'de erkekler kadınlara göre daha kolay internet ve bilgisayara ulaşabildikleri (Kuloğlu, 2001) için bu durum bu araştırmada erkek öğrencilerin bağımlılık düzeyinin daha yüksek bulunmasında etkili olmuş olabilir.

Araştırmada ikinci değişken olarak öğrencilerin öğrenim görmekte oldukları sınıf ele alınmıştır. Araştırmaya katılan öğrencilerin öğrenim görmekte olduğu sinıflara göre internet ve oyun bağımlılığı açısından anlamlı farklılık olmadığı bulunmuştur. Bu bulgu literatürdeki çalışmalarla farklılık göstermektedir. Kubey, Lavin ve Barrow'un (2001) yaptığı çalışma incelendiğinde birinci sinıfta okuyan öğrencilerin daha fazla bağıml 
oldukları bulunmuştur. Yeni bir ortama giren bireylerin bu ortamdaki kişilerle iletişim kurması ve o ortama uyum sağlaması kolay olmamaktadır. Üniversiteye yeni başlayan bireyler bu nedenle çevrelerindeki kişilerle iletişim kuramadıkları için bu eksikliği bilgisayarla gidermeye çalışabilmektedir. Kubey, Lavin ve Barrow'un araştırmasında birinci sınıf öğrencilerinin bağımlılığının diğer sınıflara göre daha fazla çıkmasında bu durum etkili olmuş olabilir. Türkiye gibi ülkelerde bireyler çevrelerindeki kişilerle kolaylıkla iletişime girer ve sorunlarını bu kişilerle paylaşabilirler. $\mathrm{Bu}$ durum da üniversiteye yeni katılan öğrencilerin yalnızlık hissetmemesine ve bu yalnızlığını farklı şekillerde giderme yolları aramamasına neden olabilir. İki araştırma arasındaki farklılık bundan kaynaklı olabilir.

Araştırmada bilgisayar ve internet bağlantısına sahip olanların internet ve bilgisayar oyun bağımlılığı puanlarının yükssek olduğu bulunmuştur. $\mathrm{Bu}$ bulgu Kim ve Kim (2002), Mumtaz (2001), Shi ve diğ. (2006) ve Grifits ve Hunt'un (1995) bulguları ile tutarlıdır. Evde bilgisayara ve internet bağlantısına sahip olan bireyler istedikleri zaman kullanım olanağına sahip olduğu için bu sonuç doğal olarak karşılanabilir. Kim ve Kim (2002) kolay internet erişimi, internet kullanım becerileri ve internet kullanım zamanının bağımlılığa yol açtı̆̆ını ifade etmektedir. $\mathrm{Bu}$ bulguda bu araştırmayı destekler niteliktedir.

Araştırmada son olarak öğrencilerin tercih ettikleri oyun türüne göre internet ve bilgisayar oyun bağımlılığı açısından anlamlı farklılık olmadığ bulunmuştur. Griffiths ve Hunt (1995), Griffiths ve diğ. (2004) araştırmalarında tek başına bilgisayar oyunu oynayanların bilgisayar bağımlılı̆̆ının daha fazla olduğunu belirtmektedirler. İki bulgu arasındaki farkın nedeni olarak batı toplumundaki bireyler etkinlikleri bireysel olarak tercih ederlerken Türkiye gibi ülkelerde ise bireyler etkinlikleri bireysel ve grup halinde yürütebilmelerinden kaynaklandığı düşünülebilir.

Araştırmada erkek öğrencilerin bağımlılık düzeyleri yüksek olduğundan daha çok desteğe gereksinim duyabilecek konumdadırlar. $\mathrm{Bu}$ yönüyle bağımlılı̆̆ı önlemek amacıyla yapılacak çalışmalarda erkek öğrencilerin daha çok dikkate alınması gerekmektedir. Bilgisayar ve internet kullanma olanağı bulunan ya da sahip olan kişilerin daha bağımlı olduğu bulgusu dikkate alınarak, bu bireylere bu araçları amaca uygun olarak kullanma becerisi kazandırmak gerektiği unutulmamalıdır. Bunu sağlamak için öğrencilere ve ailelere bu konularda seminerler ve eğitimler verilmesi, bağımlılığı önlemek için önemli unsurlardır.

İnternet ve oyun bağımlılığı bireylerin fiziksel, psikolojik ve sosyal hayatlarını olumsuz şekilde etkilemesi (Gentile ve diğerleri, 2011) nedeniyle, bu olumsuzlukların sonuçları hakkında bireylere bilgi verilmesi 
ve bu olumsuzluklardan bireylerin kurtulması için önleyici ve tedavi edici çalışmalara ihtiyaç duyulmaktadır.

Araştırmada üniversite öğrencilerinin internet ve oyun bağımlılık düzeyleri çeşitli değişkenler açısından incelenmiştir. Bu çalışmanın bulguları ülkemizde öğrencilerin en özerk oldukları, internet ve oyun oynama düzeyi açsından istedikleri gibi davranabildikleri bir dönem olan üniversite düzeyindedir. Öğrenciler bu düzeyde birçok amaç için bilgisayar ve internet kullanmaktadırlar. Özelliklede üniversite eğitimlerine katk1 sağlayacak bilgisayar ve internet kullanımı başarılarını artıracak ve mesleki gelişimlerine önemli katkı sağlayacaktır. Ancak internet ve oyun bağımlılığına dönüşen amaç dışı kullanımlar bireylerin akademik, sosyal ve mesleki hayatlarını olumsuz şekilde etkileyebilecek durumlar ortaya çıkarabilecek niteliktedir. Bu yönüyle üniversite eğitiminde bu araçların aşırı ve amaç dışı kullanımını önlemeye yönelik çalışmalara 1şık tutabilecek veriler ortaya koyulmasının yanında farklı değişkenlerin konu edildiği daha fazla çalışma ile hem farkındalığın artırılması sağlanacak hem de önlemeye yönelik çalışmaların başarılı olabilmesi için kaynak olacaktır.

Ülkemizde ilk ve orta ögretim düzeyinde bilişim teknolojileri dersinin seçmeli ders haline getirilerek bir saate indirilmesi hatta dersin ilköğretim ilk kademede tamamen kaldırılması teknolojinin amacı doğrultusunda kullanımı açısından olumsuz etkiye sahip olacak bir durumdur. Çünkü bilişim teknolojileri dersinde öğretmenlerin, teknoloji okuryazarlığı açısından amacı doğrultusunda teknoloji kullanımı, etik ve sosyal değerler açısından teknoloji ile ilgili bilgi ve beceri kazandırması hedeflenmektedir (MEB, 2007). İlköğretim düzeyinde bilişim teknolojileri ile ilgili olumlu davranış kazandırması beklenen bu dersin programdan kaldırılması ilerleyen yıllarda teknolojinin amacı dışında kullanılmasına neden olabilecek bir durumdur. Teknolojinin amacı dışında kullanımı da bireylerde bağımlılığa neden olmaktadır. Bu durumda öğrencilere doğru teknoloji kullanma becerisini öğretme sorumluluğu, farklı derslerde sınıf ve branş öğretmenlerine düşmektedir. Sınıf ve branş öğretmenlerinin bu sorumluluğu sağlıklı bir şekilde yerine getirebilmesi için öğretmen yetiştiren kurumlarda buna yönelik eğitimler verilemesi gerekmektedir. Bu eğitimlerle öğretmenlerin bağımlılığa yönelik farkındalığının artırılması amaçlanmalıdır. 


\section{KAYNAKLAR}

Anderson, J.C. ve Gerbing, D.W. (1984). The effect of sampling error on convergece, improper solutions and goodness-of-fit indices for maximum likelihood confirmatory factor analysis. Psychometrika, 49, 155-173.

Ayas, T., Çakır, Ö. ve Horzum, M.B. (2011). Ergenler için Bilgisayar Bağımlılığı Ölçeği. Kastamonu Üniversitesi Eğitim Fakültesi Dergisi.19 (2). 439-448.

Balc1, A. (1997). Sosyal bilimlerde araştırma yöntem, teknik ve ilkeler. Gözden geçirilmiş ve ilave edilmiş ikinci baskl. Ankara: TDFO Bilgisayar-yayınc1lık San. Tic. Ltd. Şti.

Büyüköztürk, Ş. (2005). Sosyal bilimler için veri analizi el kitabı. Ankara: Pegema Yayıncilik.

Brenner, V. (1997). Psychoology of computer use: XL VII. Parameters of internet use, abuse and addiction: The first 90 days of the internet usage survey. Pyschological reports, 80, 879-882.

Bryce, J. ve Rutter, J. (2006). Gender dynamics and the social and spatial organization of computer gaming. Leisure Studies, 22, 1-15.

Cao, F., Su, L., Liu, T. ve Gao, X. (2007). The relationship between impulsivity and Internet addiction in a sample of Chinese adolescents. European Psychiatry, 22, 466-471.

Chou, C. ve Hsiao, M.C. (2000). Internet addiction, usage, gratification, and pleasure experience: the Taiwan college students' case. Computers and Education, 35(1), 65-80.

Chou, C., Condron, L. ve Belland, J.C. (2005). A Review of the Research on Internet Addiction. Educational Psychology Review, 17(4), 363-388.

Chou, C. ve Tsai, M.J. (2007). Gender differences in Taiwan high school students' computer game playing. Computers in Human Behavior, 23(1), 812-824.

Chumbley, J. ve Griffiths, M. (2006). Affect and the Computer Game Player: The Effect of Gender, Personality, and Game Reinforcement Structure on Affective Responses to Computer Game-Play. Cyberpsychology \& Behavior, 9(3), 308-316.

Davis, R.A. (2001). A Cognitive-behavioral model of pathological internet use. Computers in Human Behavior, 17, 187-195.

Durdu, P., Hotamaroğlu, A. ve Çağıltay, K. (2004). Türkiye'deki Öğrencilerin Bilgisayar Oyunu Oynama Alışkanlıları ve Oyun Tercihleri: ODTÜ ve Gazi Ünivesitesi öğrencileri arası bir karşılaştırma Bilişim Teknolojileri ışığında Eğitim-2004. 97-101. 
Ferraro, G., Caci, B., D'Amico, A. ve Di Blasi, M, (2007). Internet addiction disorder: An Italian study. Cyberpsychology \& Behavior, 10(2), 170185.

Gentile, D.A., Choo, H., Liau, A., Sim, T., Li, D., Fung, D. ve Khoo, A. (2011). Pathological Video Game Use Among Youths: A Two-Year Longitudinal Study. Pediatrics, 127, 319-329.

Griffiths, M.D. (2000). Video game violence and aggression: Comments on 'Video game playing and its relations with aggressive and prosocial behaviour' by O. Weigman and E.G.M. van Schie. British Journal of Social Psychology. 39, 147-149.

Griffiths, M.D. ve Hunt, N. (1995). Computer game playing in adolescence: Prevalence and demographic indicators. Journal of Community and Applied Social Psycholog, 5, 189-193.

Griffiths, M.D., Davies, M.N.O. ve Chappell, D. (2003). Breaking the Stereotype: The Case of Online Gaming. Cyberpsychology \& Behavior, 6(1), 81-91.

Griffiths, M.D., Davies, M.N.O. ve Chappell, D. (2004). Demographic Factors and Playing Variables in Online Computer Gaming. Cyberpsychology \& Behavior, 7(4), 479-487.

Hollingsworth, W.C. (2005). The relationship between shyness and internet addiction: a quantitative study on middle and post secondary school students. Centre For Information And Technology in Education eJournal. 1(2), $\quad$ http://phpfusion.cite.hku.hk/ejournal/articles/volume1/issue2/2/ volume1_issue2_2.htm adresinden 06.04.2008 tarihinde erişilmiştir.

Horzum, M.B. (2011). İlköğretim Öğrencilerinin Bilgisayar Oyunu Bağımlılık Düzeylerinin Çeşitli Değişkenlere Göre İncelenmesi. Ĕğitim ve Bilim, 36(159), 56-68.

Hsu, C.L. ve Lu, H.P. (2007). Consumer behavior in online game communities: a motivational factor perspective. Computers in Human Behavior, 23, 1642-1659.

Karasar, N. (2004). Bilimsel araştırma yöntemi (15. Bask1). Ankara: Nobel yayın dağıtım.

Kim, S. ve Kim, R. (2002). A study of internet addiction: status, causes, and remedies. Journal of Korean Home Economics Association English Edition, 3(1), 1-19.

Kim, E.Y., Lee, Y.S., Han, D.H., Suh, D.S. ve Kee, B.S. (2006). Temperament and genetic polymorphism in korean male adolescents with internet addiction tendency. Journal of Korean Neuropsychiatr Assoc, 45(5), 468-475. 
Kubey, R.W., Lavin, M.J. ve Barrows, J.R. (2001). Internet use and collegiate academic performance decrements: early findings. Journal of Communication, 51(2), 366-382.

Kuloğlu, C. (2001). İnternet Cafeler ve İnternet Bağımlılı̆̆ı: Ankara Örneği. Yayınlanmamış Lisans Tezi. Ankara: Hacettepe Üniversitesi.

Li, N. ve Kirkup, G. (2007). Gender and cultural differences in internet use: A study of China and the UK. Computers \& Education, 48(2), 301-317.

MEB (2007). İlköğretim bilgisayar dersi (1-8. sinıflar) öğretim programı. Ankara: MEB Yayınevi.

Michael, X.Q. (2008). Demographics, motivations, addictions and usage patterns among Chinese college student MMORPG players. Unpublished theses. Chinese University of Hong Kong.

Morahan-Martin, J. ve Schumacher, P. (2000). Incidence and correlates of pathological internet use among college students. Computer and Human Behavior, 16(1), 13-29.

Mumtaz, S. (2001). Children's enjoyment and perception of computer use in the home and the school. Computers \& Education, 36, 347-362.

Onay, P.D.; Tüfekçi A. ve Çağıltay, K. (2005). Türkiye'deki öğrencilerin bilgisayar oyunu oynama alışkanlıkları ve oyun tercihleri: ODTU ve Gazi Üniversitesi öğrencileri arası karşılaştırmalı bir çalışma, Biliş̧im Teknolojileri Işı̆̆ı̆da Eğitim Konferansı, Ankara.

Passig, D. ve Levin, H. (1999). Gender interest differences with multimedia learning interfaces. Computers in Human Behavior, 15, 173-183.

Quaiser-Pohl, C., Geiser, C. ve Lehmann, W. (2006). The relationship between computer-game preference, gender, and mental-rotation ability. Personality and Individual Differences, 40, 609-619.

Rau, P.P., Peng, S. ve Yang, C. (2006). Time distortion for expert and novice online game players. Cyberpsychology \& Behavior, 9(4), 396403.

Scherer, K. (1997). College life online: Healthy and unhealthy Internet use. J. College Stud. Dev, 38(6), 655-665.

Shi, Q., Zhou, RG., Ge, Y., Qin, X.G. ve Zhang, K. (2006). Study on the relationship of internet addiction disorder and sensation seeking of middle and high school Students. Chinese Mental Health Journal, 19(7), 453-456.

Shi, Q. (2007). Why some people are addicted to computer games - an analysis of psychological aspects of game players and games. HCI International 2007, the 12th International Conference on HumanComputer Interaction was held in Beijing, P.R. China, 22-27 July. http://www.ruc.dk/upload/application/pdf/f51d6748/Qingxin_Shi_China _Paper.pdf adresinden 01.01.2009 tarihinde erilişmiştir. 
Sümer, N (2000). Yapısal eşitlik modelleri: Temel kavramlar ve örnek uygulamalar. Türk Psikoloji Yazıları, 3(6), 74-79.

Şimşek, Ö.F. (2007). Yapısal Eşitlik Modellemesine Giriş: Temel ilkler ve LIRSEL uygulamaları. Ankara: Ekinoks yayınları.

Wang, L.S.M. ve Chang, G. (2004). Lifestyles of virtual world residents: Living in the on-line game "Lineage". Cyberpsychology \& Behavior, 7(5), 592-600.

Whang, S.M. (2005). Online games dynamics in Korean society: Experiences and lifestyles in the online game world. Ed.: Gale, F. ve Fahey, S. Youth in Transition: The Challenges of Generational Change in Asia. The Association of Asian Social Science Research Councils (AASSREC). 206-227.

Wiki (2008). Video game addiction. Wikipedia. http://en.wikipedia.org/wiki/ Video_game_addiction adresinden 11.04.2011 tarihinde erişilmiştir.

Young, K. (1996). Psychology of computer use: XL. addictive use of the internet: a case that breaks the stereotype. Psychological Reports, 79, 899-902.

Young, K. (1998). Caught in the Net: How to Recognize the Signs of Internet Addiction and $a$ Winning Strategy for Recovery. New York: Wiley.

Young, K. (1999). Internet addiction: symptoms, evaluation, and treatment. Ed: vande creek ve T. Jackson. Innovations in Clinical Practice: A Source Book. Sarasota, FL: Professional Resource Pres. 19-31. 
